This apparatus differs from the one used in Dr. Squibb's works, by the use of the tube $B$ and the narrowing of the tube $C$ below the end of tube $B$. This addition was found necessary because when the tube $\mathrm{B}$ is not used the opening of the pinch cock below the thistle tube causes a momentary increase of pressure in the tube $\mathrm{C}$ until the vertical tube below $\mathrm{C}$ has been filled. This disarranges the asbestos on the platinum plate in the filter described in the Journal of the American Chemical Society, Vol. III, p. 125, and the operator is put to much trouble.

\title{
ON THE ESTIMATION OF NITROGEN IN COMPOUNDS OF THE AUROMATIC SERIES BY THE KJELDAHL METHOD.
}

\author{
By J Ames H. Stebins, JR.
}

Since the publication of Kjeldahl's method for the estimation of nitrogen I have made quite a number of analyses of fertilizersin which the nitrogen was estimated according to this process, and always with good results. At first, however, I was rather doubtful of their accuracy, and therefore made a few parallel tests by combustion with soda lime. These soon showed that the method might be relied upon, except in fertilizers containing a large amount of $\mathrm{ni}$ trates. The results obtained were invariably a little bigher than those obtained by combustion, but entirely within the range of error. Having obtained such fair results with fertilizers, I was anxious to ascertain whether it might be used to advantage in the analysis of aromatic nitrogen compounds, and thus do away with the troublesome operation of estimating the nitrogen by combustion with oxide of copper.

To what extent this process may be relied upon will be seen from the following data :

$$
\begin{gathered}
\text { Paratoluidine. } \\
1: 4 \mathrm{C}_{6} \mathrm{H}_{4}\left(\mathrm{CH}_{3}\right) \mathrm{NH}_{2}
\end{gathered}
$$

0.50 grm. perfectly dry paratoluidine, was dissolved in 20 c. c. of sulphuric acid mixture (4 vols. sulphuric acid $66^{\circ}$ B., 1 vol. fuming $\mathrm{H}_{2} \mathrm{SO}_{4}$ containing in each 20 c. c. of mixture 2 grms. $\mathrm{P}_{2} \mathrm{O}_{5}$ ), and heated to boiling until the whole mixture had become nearly colorless. Time required, $1 \mathrm{~h} .15 \mathrm{~m}$. The mixture was then oxidized as usual with $\mathrm{KMnO}_{4}$, neutralized with 140 c. c. of 16 per cent soda 
solution and distilled. The ammonia given off was collected in 50 c. c. $\frac{\mathrm{N}}{10} \mathrm{H}_{2} \mathrm{SO}_{4}$, the distillation lasting 30 minutes. The amount of sulphuric acid not neutralized by the ammonia was estimated with $\frac{\mathrm{N}}{10}$ soda solution. 50 c. c. $\frac{\mathrm{N}}{10} \mathrm{H}_{2} \mathrm{SO}_{4}$ required for neutralization 11.8 c. c. $\frac{\mathrm{N}}{10} \mathrm{NaOH}$. Therefore 38.2 c. c. of the acid had been neutralized by the ammonia.

$$
. .38 .2 \times .0014=.05348 \mathrm{~N} \text {. }
$$

Equivalent to vitrogen ............ 10.68 per cent.

Theory ............ ............ 13.17 "

The great discrepancy between the two results led me to believe that, perhaps, the amount of sulphuric acid mixture used had not been sufficient for the complete decomposition of the paratoluidine. The experiment was therefore repeated, using only $0.25 \mathrm{~g}$. in lieu of $0.50 \mathrm{~g}$. The other conditions were the same, with the exception of a little sand added to the acid mixture to prevent bumping.

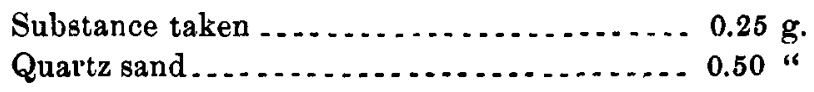

This mixture was heated for two hours. The solution, at the end of this time, had become transparent and of the color of white wine. It was then oxidized with $\mathrm{KMnO}_{4}$, and distilled after neutralization with $\mathrm{NaOH}$.

50 c. c. $\frac{\mathrm{N}}{10} \mathrm{H}_{2} \mathrm{SO}_{4}$ required for neutralization 29.7 c. c. $\frac{\mathrm{N}}{10} \mathrm{NaOH}$. Therefore $50-29.7=20.3=$ the amount of acid neutralized by the ammonia.

$$
\begin{aligned}
& 20.3 \times .0014=.02842 \mathrm{~N} . \\
& \text { Equivalent to nitrogen ............ } 11.44 \text { per cent. } \\
& \text { Theory ........................ 13.17 " }
\end{aligned}
$$

As will be seen the result obtained this time is a trifle better, but still wide of the mark. I therefore thought that the discrepancy in the amount of nitrogen obtained might be due to two things, viz.: to the volatility of the paratoluidine, or to the tenacity with which some aromatic compounds hold on to the nitrogen they contain, thus preventing a complete conversion of the nitrogen into ammonium sulphate. As, however, the paratoluidine 
enters immediately into combination with the sulphuric acid, forming a sulphate which is a much more stable compound than the original substance, the first of these two reasons would hardly hold good, and must therefore be discarded.

In order to prove that the above theory is correct two other tests were made, using compounds the nature of which would lead one to expect similar results.

Diphenylamine.

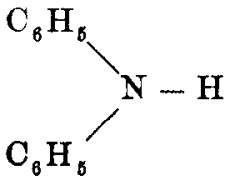

Substance taken...................... $0.25 \mathrm{~g}$.

Quartz sand.......................... 0.50 "

Heated the above with 20 c. c. of sulphuric acid mixture for $2 \mathrm{~h} .30 \mathrm{~m}$, until the contents of the flask had assumed a white wine color. Then oxidized with $\mathrm{KMnO}_{4}$, and distilled as usual.

50 c. c. $\frac{\mathrm{N}}{10} \mathrm{H}_{2} \mathrm{SO}_{4}$ required for neutralization 36.1 c. c. $\frac{\mathrm{N}}{10} \mathrm{NaOH}$. $50-36.1=13.9$ c. c. $=$ acid neutralized by the ammonia.

$$
13.9 \times .0014=.01946 \mathrm{~N} \text {. }
$$

Equivalent to nitrogen ............ 7.78 per cent.

Theory ........................ 8.28

It will be observed in this example, that the nitrogen found is much closer to theory than in the other two eases. This is probably due to the fact that the nitrogen was more readily acted upon by the sulphuric acid, thus giving a greater yield of ammonium sulphate. In the following example, however, there is again a great error, because in this case the nitrogen is very firmly bound to the two benzole nuclei, and is not sufficiently acted upon by the sulphuric acid to be entirely converted into ammonium sulphate.

\section{Azobenzole.}

$$
\mathrm{C}_{6} \mathrm{H}_{5}-\mathrm{N}=\mathrm{N}-\mathrm{C}_{6} \mathrm{H}_{5}
$$

Substance taken ...................... $0.25 \mathrm{~g}$.

Sand ............................... 0.50 "6

Heated mixture for $3 \mathrm{~h}$. $30 \mathrm{~m}$. with 20 c. c. sulphuric acid, oxidized and distilled. 
50 c. c. $\frac{\mathrm{N}}{10} \mathrm{H}_{2} \mathrm{SO}_{4}$ required for neutralization 25 . c. c. $\frac{\mathrm{N}}{10} \mathrm{NaOH}$.

$$
25 \times .0014=.0350 \mathrm{~N} \text {. }
$$

Equivalent to nitrogen............ 14 per cent.

Theory ....................... 15.38 "

Having obtained such poor results from compounds in which the nitrogen was firmly bound to the benzole nuclei, it seemed probable that in using substances in which the nitrogen might be more easily driven off better results might be obtained. For this purpose the nitro- compounds were chosen.

$$
\begin{gathered}
\text { Dinitrobenzole }(a) \text {. } \\
\mathrm{C}_{6} \mathrm{H}_{4}\left(\mathrm{NO}_{2}\right)_{2}
\end{gathered}
$$

Substance taken.......................... $0.25 \mathrm{~g}$.

Quartz sand ........................... $0.50 "$

Heated the above to boiling with 20 c. c. of sulphuric acid mixture, oxidized with $\mathrm{KMnO}_{4}$, and distilled as usual.

50 c. c. $\frac{\mathrm{N}}{10} \mathrm{H}_{2} \mathrm{SO}_{4}$ required for veutralization 36 c. c. $\frac{\mathrm{N}}{10} \mathrm{NaOH}$.

$50-36=14$ c.c. $=$ acid neutralized by the ammonia.

$$
14 \times .0014=.0196 \mathrm{~N} \text {. }
$$

Equivalent to nitrogen ............ 7.84 per cent.

Theory ...................... 16.66 "

This great discrepancy led to the conclusion that the small yield of nitrogen was simply due to the fact that a part of the nitrogen had been driven off by the sulphuric acid as NO. It was therefore suggested to me to mix with the sulpluric acid a substance, which, upon heating, would evolve a large volume of sulphuric acid, and thus act as a reducing agent upon the NO.

The substance best suited for this purpose is pure cane sugar. The results obtained in using this slight modification were quite satisfactory, and encouraged me to go on.

$$
\begin{gathered}
\text { Dinitrobenzole }(b) \text {. } \\
\mathrm{C}_{6} \mathrm{H}_{4}\left(\mathrm{NO}_{2}\right)_{2}
\end{gathered}
$$

Substance taken ..................... $0.25 \mathrm{~g}$.

Sugar ............................. $0.50 "$

Sand ................................. $0.50 "$

Heated to boiling for 1 h. $30 \mathrm{~m}$, oxidized with $\mathrm{KMnO}_{4}$ and distilled. 
50 c. c. $\frac{\mathrm{N}}{10} \mathrm{H}_{2} \mathrm{SO}_{4}$ required 21.2 c. c. $\frac{\mathrm{N}}{10} \mathrm{NaOH}$. $50-21.2=28.8=$ acid neutralized by the ammonia. $28.8 \times .0014=.04032 \mathrm{~N}$.

Equivalent to nitrogen ............ 16.12 per cent.

Theory ........................ 16.66 "

The amount of nitrogen found is a little low, still the error is not much larger than sometimes occurs in making a combustion with oxide of copper.

Metanitraniline.

$$
1: 3 \mathrm{C}_{8} \mathrm{H}_{4}\left(\mathrm{NO}_{2}\right) \mathrm{NH}_{2}
$$

Substance taken........................ $0.25 \mathrm{~g}$.

Sugar.............................. $0.50 "$

Sand .... . . . . . . . . . . 0.50 "

Heated to boiling for two hours, with 20 c. c. of sulphuric acid mixture, and treated as usual.

50 c. c. $\frac{\mathrm{N}}{10} \mathrm{H}_{8} \mathrm{SO}_{4}$ required for neutralization 14.2 c. c. $\frac{\mathrm{N}}{10} \mathrm{NaOH}$. $50-14.2=35.8$ c. c. $=$ acid neutralized.

$35.8 \times .0014=.05012 \mathrm{~N}$.

Equivalent to nitrogen . . . . . . . . ... 20.04 per cent.

Theory ....................... 20.29 "

Orthonitrophenole.

$$
1: 2 \mathrm{C}_{6} \mathrm{H}_{4}(\mathrm{OH}) \mathrm{NO}_{2}
$$

Substance taken...................... $2.25 \mathrm{~g}$.

Sugar.............................. 0.50 "

Sand................................. 0.50 "

Heated with 20 c. c. sulphuric acid mixture, etc.,

50 c. c. $\frac{\mathrm{N}}{10} \mathrm{H}_{2} \mathrm{SO}_{4}$ required for neutralization 32.6 c. c. $\frac{\mathrm{N}}{10} \mathrm{NaOH}$.

$50-32.6=17.4$ c. c. $=$ acid neutralized by the $\mathrm{NH}_{3}$.

$$
17.4 \times .0014=.02436 \mathrm{~N} \text {. }
$$

Equivalent to nitrogen ............. 9.74 per cent.

Theory ........................ 10.07 "

It will be seen therefore that the Kjeldahl method will only yield correct results with such bodies as are easily decomposed, giving off their nitrogen in the shape of ammonium sulphate. The volatility of a compound in this process is not a source of error, for Kjeldahl bimself analyzed such bodies as trimethylamine and obtained correct results. 